\title{
Preços administrados e discricionariedade do Executivo
}

\author{
PAULO FURQUIM DE AZEVEDO \\ FELIPPE C. SERIGATI*
}

RESUMO: Durante o primeiro mandato da presidente Dilma, os preços administrados foram utilizados como um instrumento para cumprir a meta de inflação, de modo a subordinar as políticas industriais para finalidades macroeconômicas de curto prazo. Esta estratégia foi ineficaz para controlar a inflação e distorceu decisões de investimento e consumo. O artigo mostra que os preços tendem a desviar-se mais, quanto maior for seu peso no índice de preços, e tendem a variar de forma consistente com os ciclos políticos. O artigo conclui com sugestões de políticas para controlar o efeito negativo de desvios de critério do governo para determinar os preços administrados.

PALAVRAS-CHAVE: preços administrados; meta de inflação; ciclos eleitorais; discrição governo.

ABSTRACT: Administered prices and government discretion. Administered prices during the first term of President Dilma were used as an instrument to meet inflation target, so as to subordinate industrial policies to short run macroeconomic aims. This strategy was ineffective to control inflation and distorted investment and consumption decisions. The article shows that prices tend to deviate more the larger their weight in the price index, and tend to vary consistently with the political cycles. The article concludes with policy suggestions to control the negative effect of deviations of government discretion to determine administered prices.

KEYWORDS: administered prices; inflation target; government discretion; electoral cycles. JEL Classification: E31; L32.

\section{INTRODUÇÃO}

Em 22/06/2012, a Petrobras anunciou um ajuste de 7,83\% no preço da gasolina na refinaria. Simultaneamente, o governo reduziu a zero a alíquota da Contri-

\footnotetext{
* Respectivamente, INSPER e CNPq, e-mail paulofa1@insper.edu.br - Brasil; Escola de Economia de São Paulo da FGV, e-mail felippe.sergitati@fgv.br. Submetido: 18/agosto/2014; Aprovado: 12/setembro/2014.
} 
buição de Intervenção no Domínio Econômico (Cide), imposto incidente sobre a comercialização de gasolina e diesel, anulando o efeito do primeiro aumento sobre o preço de revenda ao consumidor final. Na justificativa para a medida, o Ministério da Fazenda argumentava que, dessa forma, poderia reduzir a defasagem dos preços da gasolina, cujo custo de produção estava pressionado por forte alta do petróleo no mercado internacional, e, ao mesmo tempo, evitar que esta recomposição de preços tivesse impacto inflacionário.

Este caso ilustra a política do primeiro mandado do governo Dilma em relação aos preços administrados: a subordinação dos fundamentos microeconômicos, que deveriam orientar a precificação de serviços sobre os quais o governo detém alguma discricionariedade, aos problemas macroeconômicos de curto prazo. $\mathrm{O}$ resultado, como procura mostrar este estudo, foi desastroso, seja para eficiência dos mercados, preocupação microeconômica, seja para as questões macroeconômicas de longo prazo. Por meio da análise de preços administrados selecionados, este artigo procura identificar possíveis defasagens e suas consequências econômicas, bem como os elementos que orientam os governos no uso de sua discricionariedade de precificar os serviços sobre os quais detém controle.

A condução dos preços administrados no governo Dilma tem sido objeto de grande controvérsia, sobretudo por seu uso como mecanismo de controle da inflação. Por definição, preços administrados são aqueles que "são insensíveis às condições de oferta e de demanda porque são estabelecidos por contrato ou por órgão público" (Banco Central, 2014, p. 2). Entre estes, é fundamental distinguir aqueles sobre os quais o governo possui alguma discricionariedade e, portanto, pode utilizar o seu poder de precificar como instrumento de demais políticas de seu interesse. Este é o caso do preço de produtos e serviços de empresas estatais, como a Petrobras e a Empresa Brasileira de Correios e Telégrafos (doravante, Correios), ou de empresas concessionárias em que o modelo regulatório não retira do poder público a discricionariedade de precificar, como é o caso de empresas de transporte urbano municipal.

Caso bastante distinto é aquele em que as concessionárias estão sujeitas a uma regra de reajuste de preços, definida no marco regulatório setorial, sobre a qual a administração direta possui pouca ou nenhuma discricionariedade, como é o caso das tarifas de energia elétrica ou de pedágios. Nesses casos, o contrato de concessão define os parâmetros do reajuste de preços, que pode contar com a participação da agência de regulação setorial (e.g., Aneel ou Anatel), via de regra uma autarquia independente. Não é este tipo de política de preços administrados que desperta a crítica dos analistas econômicos. A controvérsia recai sobre o uso ou abuso do poder de definir preços por parte do governo e, portanto, sobre os preços administrados sobre os quais o governo tem discricionariedade de precificação.

Como se verá ao longo deste artigo, o poder de o governo definir o preço de alguns serviços e produtos não é um problema em si, podendo se justificar como um instrumento que torne mais eficaz políticas públicas diversas, como a política industrial ou tecnológica. Há, contudo, um problema quando o governo utiliza este poder de precificação para atender a objetivos estranhos à política setorial, como o mero controle de preços ou os ciclos eleitorais. Nesses casos, a manipulação dos preços administrados distorce a política setorial, com resultados negativos ao 
investimento e, portanto, crescimento econômico, e pode também, o que é possivelmente mais grave, afetar de modo espúrio o processo político.

As análises dos preços de energia, derivados de petróleo, Correios e tarifas de ônibus urbanos indicam que o exemplo da Cide, citado no primeiro parágrafo deste artigo, não é um caso isolado. Há evidências de que preços administrados têm sido utilizados de modo subordinado à política de controle da inflação e, em menor escala, para como estratégia político-eleitoral. Por outro lado, não se trata de um fenômeno generalizado, havendo casos de preços cujos reajustes parecem acompanhar mais de perto a política setorial e as condições de oferta e demanda.

O restante deste artigo divide-se em três seções. A próxima discute, em uma perspectiva geral, os motivos e as consequências de se alocar ao governo o poder de decidir unilateralmente os preços de serviços de utilidade pública. Essa seção também indica as possíveis fontes de distorção no exercício do poder de precificar e suas prováveis consequências econômicas. A terceira seção analisa a evolução recente de alguns preços administrados selecionados - derivados de petróleo, energia elétrica, Correios e tarifas de ônibus urbanos - procurando identificar os casos em que é possível observar alguma distorção relevante e sua possível motivação. A quarta seção discute as implicações de política dos resultados do estudo, com atenção ao desenho da regulação setorial e ao incentivo para o uso apropriado da capacidade de definir preços por parte do governo.

\section{“ADMINISTRAR” PREÇOS: UMA VISÃO NORMATIVA E POSITIVA}

O tema de preços administrados no primeiro mandato do governo Dilma normalmente vem associado a um diagnóstico de "defasagem", a qual, além de comprometer a política setorial, que tem nesses preços um instrumento fundamental, reduziria os graus de liberdade para um ajuste macroeconômico. Para se avaliar a pertinência deste diagnóstico, é necessário primeiro definir o que é "defasagem" de preços e como mensurá-lo. A este tópico se dedica a primeira parte desta seção. Em seguida, são apresentadas possíveis consequências da existência de defasagem, na tentativa de identificar custos e benefícios da manipulação de preços administrados. Finalmente, a seção aponta para possíveis motivos para que o governo, no uso de sua discricionariedade, opte por manter preços em níveis inferiores ao que seria desejável do ponto de vista normativo.

Preços administrados são assim definidos por serem determinados por um ente público ou por um contrato de longo prazo, tipicamente entre o Estado e concessionários de serviço público. Interessa a esta discussão, sobretudo, o primeiro tipo, os preços sobre os quais o governo possui alguma discricionariedade e, portanto, pode deliberadamente alterá-lo conforme a conveniência política, seja como instrumento de apoio às políticas públicas, seja para fins político-eleitorais. A questão que se coloca é como qualificar um preço administrado como "defasado", o que requer definir um preço de referência, um preço que se possa denominar "ajustado".

Esse problema não se coloca no caso de preços de mercados competitivos, que flutuam livremente conforme as condições de oferta e demanda. $\mathrm{Na}$ ausência de falhas de mercado, o preço de equilíbrio, fruto da livre interação entre oferta e 
demanda, é aquele que maximiza o bem-estar social. Este, contudo, não é o caso de preços administrados, cuja existência, via de regra, decorre justamente da presença de falhas de mercado, que justificam a discricionariedade do poder público em sua determinação.

Um critério para se definir um preço administrado "ajustado", em analogia com o preço de um mercado competitivo, seria considerar aquele que maximizaria o bem-estar social. Por definição, qualquer preço diferente deste resultaria em menor bem-estar para a sociedade e, portanto, haveria ganhos em ajustá-lo em direção a este preço de referência. Esta tarefa, contudo, é suficientemente difícil e complexa para ser realizada para um único serviço de utilidade pública, que dirá para o conjunto dos preços administrados, como se propõe este artigo.

Para não desviar o artigo de seu foco principal, opta-se aqui pela comparação da evolução dos preços administrados com algum parâmetro de custo de produção ou com um índice de preços. A análise não pretende concluir, portanto, se preços administrados estão distantes - e o quão distantes — do preço ótimo do ponto de vista social, mas apenas mostrar se tais preços variaram de modo inconsistente com seus custos ou demais preços e se tais variações são, por outro lado, explicadas por uma racionalidade político-eleitoral. Por exemplo, se o preço da gasolina aumenta menos que o preço do petróleo, seu principal custo, há sinais de aumento da defasagem deste preço administrado. Além disso, é interessante indagar se esta defasagem tem relação com o calendário eleitoral ou com a existência de pressão inflacionária, o que revelaria alguma racionalidade do poder público no uso de sua discricionariedade na determinação de preços administrados.

Uma vez identificada eventual defasagem de preços administrados, deve-se questionar se, do ponto de vista normativo, esta defasagem é desejável ou não. A alocação de discricionariedade para que o poder público possa definir determinados preços administrados não é per se uma virtude ou um vício da política pública. O desvio do preço administrado em relação aos seus custos pode, eventualmente, atender ao propósito de uma política setorial, a qual pode ser a razão essencial para que se alocasse o poder de precificar ao executivo. Os exemplos são variados, como a garantia de oferta de nafta, a um preço favorável, como parte da política de desenvolvimento da indústria petroquímica no Brasil (Erber, 1993; Wongtschowski, 1998), ou a de energia elétrica para garantir a competitividade nos primeiros anos da produção de alumínio no Brasil (Castro, 1968). Também no caso de haver externalidades positivas em serviços sujeitos a preços administrados, do mesmo modo se justificaria, do ponto de vista normativo, a prática de preços inferiores aos custos privados de produção.

A avaliação da pertinência do uso de desvios de preços administrados para fins de política setorial é uma atividade que, em si, desviaria este texto de seu objetivo principal. Como alternativa, este artigo evita avaliar a adequação de cada política setorial e, consequentemente, o papel que desvios dos preços administrados exerceriam em cada uma dessas políticas. Seu foco é a identificação de desvios que muito provavelmente não se devem à política setorial, por serem sensíveis ao calendário eleitoral ou à política macroeconômica, como o controle da inflação ou do desemprego. Em síntese, a análise empírica aqui apresentada procura discriminar os desvios ou defasagens de preços administrados que não decorram da políti- 
ca setorial, mas que sejam primariamente motivados pela política macroeconômica ou pelas circunstancias político-eleitorais. Argumenta-se aqui que o uso de preços administrados nessas situações, como um assessório à política macroeconômica ou circunstancias políticas, é sempre indesejável, o que significa caracterizar desvios de preços administrados dessa natureza como erros de política pública.

Como ponto de partida, é necessário reconhecer os custos de se definir preços administrados de modo inconsistente com a política setorial que serviu de legitimação para a atribuição de discricionariedade ao Poder Executivo. O exemplo da desoneração da Cide sobre a gasolina, em 2012, citada na introdução deste artigo, ilustra essa situação. Ali havia uma pressão de custos de produção, decorrente da persistente alta do preço do petróleo, que gerava perdas insustentáveis sobre a Petrobras. Ao mesmo tempo, a inflação brasileira no início de 2012 estava próxima ao teto da meta estabelecida para o Banco Central. A escolha do governo foi, portanto, aumentar o preço da gasolina na refinaria, o que atenuaria as perdas da Petrobras, e zerar a incidência da Cide, de modo a não pressionar a inflação.

Ao fazer isso, o governo parece ter ignorado por completo a própria motivação que deu origem à Cide, cujo papel microeconômico é o de uma tarifa pigouviana. O consumo de gasolina está associado a algumas importantes externalidades negativas, sobretudo de natureza ambiental, como poluição do ar em zonas urbanas e emissão de gases de efeito estufa. Em outras palavras, o custo privado de se produzir gasolina é inferior ao seu custo social, o que resulta em um consumo, na ausência de qualquer intervenção pública, superior ao que seria o socialmente desejável. Em contraposição, o etanol de cana-de-açúcar, por ser um combustível renovável e com balanço energético eficiente, é capaz de capturar gases de efeito estufa e está associado a outras atividades realizadas nas usinas sucroalcooleiras, como a cogeração de energia elétrica, que são mais desejáveis do ponto de vista social. Dado que etanol e gasolina são substitutos quase perfeitos para os proprietários de veículos flex fuel, na ausência de qualquer intervenção, a sociedade consumiria gasolina em demasia e pouco ou nenhum etanol, mesmo sendo o seu consumo desejável do ponto de vista social.

Uma solução para esse problema é a adoção de impostos indiretos sobre a gasolina, com o propósito de aproximar o custo privado do custo social e, assim, mitigar as distorções causadas pelas externalidades negativas. A Cide cumpria este papel, ao incidir sobre a gasolina e não sobre o etanol, tornando o preço relativo entre ambos mais favorável ao consumo de etanol, o que é socialmente desejável. A função microeconômica da Cide, portanto, é afetar o preço relativo entre derivados de petróleo e seus substitutos, e, deste modo, dar os sinais corretos para consumidores utilizarem mais etanol e para produtores investirem no aumento da capacidade produtiva desse produto. Ao fazer esta afirmação, não se pretende negar que o esforço do Estado em criar a Cide tenha também - e até predominantemente - um propósito arrecadatório. Trata-se apenas de reconhecer o seu papel em afetar o preço relativo entre etanol e gasolina e, deste modo, desempenhar importante função na política energética.

A desoneração da Cide em 2012 foi explicitamente orientada para um fim macroeconômico, atenuar o impacto inflacionário de um preço administrado. Seu custo foi microeconômico. Ao modificar o preço relativo entre etanol e gasolina, a 
desoneração da Cide estimulou o consumo de gasolina em níveis superiores ao socialmente desejável e inibiu investimentos em etanol. Diversas evidências corroboram esse entendimento. Em 2013, a Petrobras aumentou consideravelmente a importação de gasolina, reflexo do elevado consumo doméstico. Essa situação, dada a defasagem dos preços domésticos (administrados) em relação aos internacionais, teve por efeito agravar as já combalidas contas da estatal. Paralelamente, a indústria de etanol vivia uma de suas mais graves crises, cujas causas são certamente mais amplas do que a desoneração da Cide, mas que teve nesta um de seus importantes componentes. É particularmente interessante notar que a crise foi, sobretudo, uma crise de investimento, decorrente da baixa rentabilidade e da incerteza com relação aos preços futuros. Mais do que um prejuízo à oferta de curto prazo de etanol, a subordinação da política energética à política macroeconômica, por meio da contenção dos preços de derivados de petróleo, prejudica a oferta futura de etanol, com consequências deletérias à matriz energética, ao emprego e à renda gerados por este importante setor industrial.

Não bastassem os efeitos indesejáveis sobre as decisões de consumo e investimento, a manipulação de preços administrados é, ademais, ineficaz para o controle sustentável da inflação. As condições de custo e demanda que motivam a pressão para elevação desses preços permanecem presentes, mesmo que uma decisão governamental impeça o reajuste. Ainda que temporariamente a inflação não receba o impulso do aumento do preço administrado, não são resolvidas as condições que exercem a pressão pelo aumento. No momento que os preços são liberados, a pressão ocorrerá, com o agravante de a oferta do serviço que sofreu a defasagem de preço estar ainda mais constrangida por falta de incentivos para investimentos e ampliação da capacidade produtiva. É o que se nota no início do segundo mandato do governo Dilma, quando o discurso econômico muda acentuadamente e passa-se a advogar pela chamada "realidade tarifária". O realinhamento dos preços administrativos é inevitável em algum momento e com ele vem a pressão inflacionária que se procurava evitar em um primeiro momento.

Também indesejável é o uso dos preços administrativos para fins político-eleitorais. Admitindo-se que o eleitorado avalia o político em exercício pelas condições que lhe afetam direta e contemporaneamente, o represamento de reajustes de preços administrados pode ser estratégico em momentos eleitorais ou de crise política, em que o valor do apoio popular é especialmente importante. Tal estratégia não surtiria efeito se o eleitor conseguisse avaliar que preços administrados seriam reajustados no futuro e que há custos econômicos derivados da distorção dos preços relativos, conforme argumentado há pouco. Contudo, o conhecimento necessário para estabelecer essas relações passa longe do alcance da maior parte do eleitorado, problema agravado pelo conflito de informações, muitas vezes estratégico, tão comum em períodos eleitorais. Em síntese, é racional que a discricionariedade do Executivo na determinação de preços administrados seja também utilizada para fins políticos eleitorais.

Os custos dessa espécie de uso de preços administrados são, possivelmente, ainda mais gravosos à sociedade do que os decorrentes da distorção dos sinais de preços para as decisões de consumo e investimento. A distorção aqui introduzida 
é de ordem política, ao se provocar um viés no processo eleitoral, em favor do político incumbente, que pode modificar o resultado das eleições. Em última análise, o uso de preços administrados para fins eleitorais é um prejuízo à democracia.

A próxima seção avalia as variações dos preços administrados em relação a custos de produção ou ao índice de preços, procurando identificar se tais variações decorreriam de uma motivação político-eleitoral ou de subordinação da política setorial à política macroeconômica de curto prazo, ambas hipóteses em que se configuraria um abuso do uso da discricionariedade na determinação de preços administrados pelo governo executivo.

\section{PREÇOS ADMINISTRADOS NO BRASIL: UMA ANÁLISE DO PERÍODO DE 2000 A 2014}

Há defasagem de preços administrados no Brasil? Se sim, o que motivaria esta defasagem? Estas são as duas questões que orientam esta seção. Conforme exposto na segunda seção, interessa a análise dos preços sobre os quais o governo possui alguma discricionariedade e, por isso, poderia determiná-los em função de interesses da política setorial, macroeconômica ou político-eleitorais. Esta seção procura identificar as eventuais defasagens dos preços administrados e discriminar as hipóteses de uso estratégicos da discricionariedade por parte do governo.

Para tanto, foram selecionados alguns dos preços administrados, mais especificamente os preços de derivados de petróleo, de energia elétrica residencial, dos Correios e de passagens de ônibus urbanos. Esses preços permitem análises reveladoras a respeito da motivação do Executivo para o exercício de sua discricionariedade na determinação desses preços. Dessa análise é possível também derivar implicações para o desenho das políticas públicas.

\section{Dados}

Para a análise da evolução dos preços administrados, foram utilizados os levantamentos feitos pelo IBGE para o cálculo do IPCA, que contemplam os quatro serviços aqui analisados: derivados de petróleo, energia elétrica residencial, serviço dos Correios e passagens de ônibus urbanos. Além desse conjunto de preços administrados, foram também utilizados preços de insumos ou produtos concorrentes, quando possível, a fim de avaliar se as variações de preços administrados estariam relacionadas a alguma variação de custos de produção ou de condições de demanda. No caso de preços cujos ajustes estão sujeitos a regras pré-definidas, que supostamente retiram a discricionariedade do executivo para a determinação de preços, foram também analisados os índices contratualmente previstos para reajustes nos contratos de concessão.

Para o caso dos derivados de petróleo, foi coletada junto à U.S. Energy Information Administration (EIA) a série do preço internacional do petróleo, tendo a variação da taxa de câmbio por controle. Além disso, foram utilizados os preços 
do etanol hidratado, também parte dos levantamentos do IBGE para a composição do IPCA. Entre os preços administrados analisados, os de derivados de petróleo, de serviço de correios e os de passagens de ônibus urbanos são aqueles em que o executivo goza de maior liberdade para definir a periodicidade e magnitude dos ajustes de preços. De acordo com o Alves et al. (2013, pp. 7-9), a Petrobras busca alinhar os preços dos derivados de petróleo (no caso, gasolina, óleo diesel e gás liquefeito de petróleo - GLP) à tendência de longo prazo apresentada pelos respectivos preços internacionais com o objetivo de suavizar as flutuações dos preços dos combustíveis no mercado doméstico. Essa estratégia leva em consideração as variações da taxa de câmbio, do valor da gasolina no mercado externo e da cotação internacional do petróleo. Estes são, contudo, apenas princípios que orientam a precificação da Petrobras, não constituindo qualquer vinculação formal às ações da companhia.

No caso da energia elétrica residencial, foi utilizada a série de preços da energia elétrica no mercado livre, disponível na Câmara de Comercialização de Energia Elétrica (CCEE), que pode ser utilizada como uma proxy para o seu custo marginal. Além disso, entre os produtos analisados, a energia elétrica é a que conta com o modelo regulatório que mais claramente retira a discricionariedade do Executivo para intervenções em preços. De acordo com o Alves et al. (2013, pp. 12-15), a exploração do serviço público de distribuição de energia elétrica é realizada com base no contrato de concessão entre a União e a empresa distribuidora, fixando os direitos e obrigações.

Esses contratos, regulados pela Agência Nacional de Energia Elétrica (Aneel), estabelecem três mecanismos de atualização das tarifas: (a) reajuste tarifário anual; (b) revisão tarifária periódica; e (c) revisão tarifária extraordinária. No caso de reajuste tarifário anual, são considerados cenários para as variações dos custos não gerenciáveis (encargos setoriais e de uso das redes elétricas e as compras de energia) e a variação do IGP-M para os custos gerenciais (despesas de operação e manutenção, remuneração do capital, cota de depreciação, além das despesas com investimentos em pesquisa e desenvolvimento (P\&D) e eficiência energética e com o PIS/ Cofins), descontando-se o fator de produtividade fixado pela Aneel. A fim de captar o modelo de reajuste previsto nos contratos de concessão, sobre os quais o Executivo tem pouca discricionariedade para intervir, foi utilizada variação acumulada do IGP-M do ano anterior, como parâmetro para identificação de eventuais desvios no nível dos preços administrados.

No caso dos Correios, há também uma regra explícita de reajuste, dada pela variação do IPCA nos 12 meses anteriores ao mês de março de cada ano (Alves et al., 2013, p. 19), a qual foi utilizada para identificação de desvios deste preço administrado. Nota-se aqui, contudo, uma diferença fundamental com relação à energia elétrica. Enquanto a primeira opera segundo um modelo regulatório clássico, em que uma agência de regulação independente zela por contratos de concessão com empresas públicas e privadas variadas, a Empresa Brasileira de Correios e Telégrafos é uma estatal que tem reajuste de seus preços - e, obviamente, a sua 
direção - sob o controle direto do Executivo. Dessa forma, há considerável discricionariedade deste na determinação de seus preços.

Finalmente, os preços das passagens de ônibus urbanos estão tipicamente sob o controle do poder municipal, não havendo regra explícita e comum para os reajustes de preços. Para fins de identificação de eventual defasagem desses preços, foram utilizadas as séries de preço de revenda de óleo diesel, o principal componente do custo do serviço de transporte urbano, para os municípios de São Paulo, Rio de Janeiro, Belo Horizonte, Curitiba e Fortaleza. Esses preços foram também obtidos por meio dos levantamentos do IBGE para a composição do IPCA.

Sempre que possível, foram utilizadas as séries começando em dezembro de 1994, para captar completamente a variação de 1995, o primeiro ano após o período da hiperinflação. Quando as séries eram mais curtas, foram usadas todas as observações disponíveis:

- Óleo diesel: a partir de dezembro de 1999;

- Serviço dos Correios: a partir de dezembro de 1999;

- Passagens de ônibus urbanos: a partir de dezembro de 1996;

- Óleo diesel em São Paulo e Belo Horizonte: a partir de dezembro de 2000;

- Óleo diesel em Curitiba e Fortaleza: a partir de dezembro de 2006.

\section{Resultados}

Antes de uma análise de cada preço administrado, é conveniente identificar se há algum movimento geral, observável a partir de dados agregados, que responda, ainda que parcialmente, às questões levantadas por este artigo.

Tomando-se a série do IPCA de 1999 a 2014, não é possível imputar uma racionalidade político-eleitoral ou de controle inflacionário para o conjunto dos preços administrados, de modo consistente, ao longo desse período. Conforme se nota na Figura 1, não há uma regularidade que indicaria contenção de preços administrados em anos de eleições e nem tampouco maior controle sobre eles em períodos em que o IPCA supera a meta de inflação fixada para o Banco Central, as duas hipóteses de uso impróprio de preços administrados que este artigo investiga.

A mesma Figura 1, contudo, revela que há dois momentos distintos na série do IPCA. Até 2006, inclusive, preços administrados tiveram aumentos sistematicamente acima dos preços livres. A situação se inverte por completo entre 2007 e 2014, quando os preços administrados, com a única exceção de 2009, tiveram aumentos inferiores aos dos preços livres. Em outras palavras, até 2006 os preços administrados pressionavam a inflação, subindo mais do que os preços livres. Após 2007, ao contrário, os preços administrados passaram a segurar a inflação, tendo os preços livres, em algumas oportunidades, superado o teto da meta de inflação.

Este é justamente um período de inflexão da política macroeconômica, no segundo mandato do governo Lula, em que há relaxamento do ajuste fiscal e progressiva redução da taxa de juros. Do ponto de vista microeconômico, é também o período de políticas setoriais idiossincráticas, ilustradas pelas sucessivas alterações de 
alíquotas do Imposto sobre Produtos Industriais (IPI) e alterações de regras regulatórias, como, por exemplo, regras de conteúdo nacional ou a antecipação das concessões de energia elétrica. Este é também o período em que preços administrados parecem ter sido utilizados de modo subordinado à política macroeconômica, como instrumento de manutenção da inflação dentro da faixa fixada ao Banco Central.

Figura 1: Evolução do IPCA, dos preços administrados, dos preços livres e da meta de inflação.

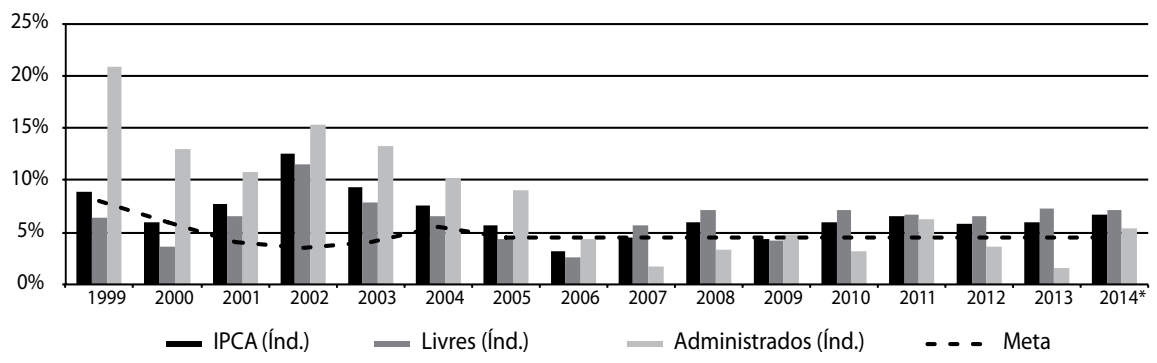

Fontes: IBGE e Banco Central.

A análise de preços administrados de modo agregado, contudo, não permite discriminar os preços sobre os quais o governo possui discricionariedade em sua determinação, como é o caso de derivados de petróleo, daqueles em que há uma regra de reajuste que limita a ação do Executivo, como é o caso da energia elétrica residencial. Passa-se agora à análise em separado de quatro tipos diferentes de preços administrados - derivados de petróleo, energia elétrica, Correios e passagens de ônibus urbanos, o que permite uma avaliação mais precisa das hipóteses de uso da discricionariedade na determinação de preços por parte do governo.

\section{Derivados de petróleo}

Para se identificar desvios do preço de derivados de petróleo, foi feita uma comparação com os preços do petróleo do mercado internacional, devidamente ajustados pela taxa de câmbio. Foram analisados os preços da gasolina, diesel e do gás liquefeito de petróleo (GLP).

A Figura 2 mostra, em três gráficos, essa comparação, tomando-se dezembro de 1994 como base para o índice de preços. Nota-se, primeiramente, que os preços dos derivados de petróleo apresentam uma volatilidade claramente menor do que os do petróleo cru, o que é consistente com a política da Petrobras de não repassar flutuações conjunturais de preços ao mercado doméstico. Esta política não deve ser objeto de críticas visto que ela não implica modificações no preço relativo de longo prazo, aquele que é relevante para as decisões de investimento. Dessa forma, a Petrobras atua reduzindo o risco de preço no mercado doméstico, o que pode ser desejável às empresas que têm nos derivados de petróleo um importante componente de seus custos de produção. 
O que mais chama a atenção na Figura 2 é a diferença observada entre os três derivados de petróleo. Enquanto o diesel e, em menor grau, o GLP, seguem de perto as variações do preço do petróleo no mercado internacional, ainda que com menor volatilidade, o preço da gasolina apresenta comportamento nitidamente diferente, em que se sobressai a defasagem entre seu preço e o de seu principal insumo. Dado que a composição de custos de produção é a mesma para os três produtos, todos obtidos por meio do refino do petróleo, e que não houve nenhum choque de demanda que diferenciasse os derivados de petróleo neste período, há uma clara indicação de defasagem nos preços da gasolina, não identificada, ao menos na mesma intensidade, nos preços do diesel e do GLP.

Uma possível explicação para esse comportamento distinto entre os derivados de petróleo é o seu peso no cálculo do IPCA ${ }^{1}$. Enquanto a gasolina é um dos produtos com maior participação individual na composição do índice $(3,7721)$, o GLP tem participação três vezes menor $(1,1046)$ e o diesel de apenas 0,1448 , ou seja, 26 vezes menor que a participação da gasolina. Há, portanto, evidência de que a política setorial, que tem no preço relativo um de seus importantes componentes, estaria subordinada à política macroeconômica de curto prazo, mais especificamente ao controle artificial da inflação.

A palavra "artificial" tem aqui duplo e relevante sentido. Não apenas o controle da inflação não tem efeito duradouro, por não tratar das causas da pressão inflacionária, como também revela que a preocupação do governo é com o índice utilizado para balizar a meta de inflação, o qual é invariavelmente uma expressão imprecisa do fenômeno concreto da inflação. O comportamento dos preços de derivados de petróleo mostra que a preocupação do governo não é primariamente a inflação - aumento generalizado do nível de preços —, visto que o preço do diesel, cujo aumento foi significativamente maior do que o da gasolina, tem efeito de médio prazo no preço de inúmeros produtos, por ser um importante componente do custo de transporte. O diesel, contudo, tem participação direta ínfima no IPCA e, portanto, seu impacto imediato sobre a inflação é menor. O problema aparecerá, é claro, a médio prazo, na elevação do custo de transportes para os diversos produtos.

A subordinação da política setorial à política macroeconômica de curto prazo tem seus efeitos mais evidentes na indústria sucroalcooleira, cuja rentabilidade foi profundamente afetada pela política de restrição a aumentos no preço da gasolina. Uma vez que mais da metade da frota automotiva é composta de veículos flex fuel, o etanol hidratado tornou-se um substituto próximo à gasolina e, como tal, tem seus preços fortemente correlacionados ao preço da gasolina. É o que mostra a Figura 3, em que é evidente como o preço do etanol, estabelecido livremente pelas condições de oferta e demanda, tende a acompanhar o preço administrado da ga-

\footnotetext{
${ }^{1}$ Todos os pesos apresentados no texto são relativos ao levantamento do IBGE para o cálculo do IPCA em dezembro de 2014.
} 
Figura 2: Evolução dos derivados do petróleo no mercado doméstico e do petróleo no mercado internacional

Evolução do preço da gasolina nacional vs. petróleo internacional

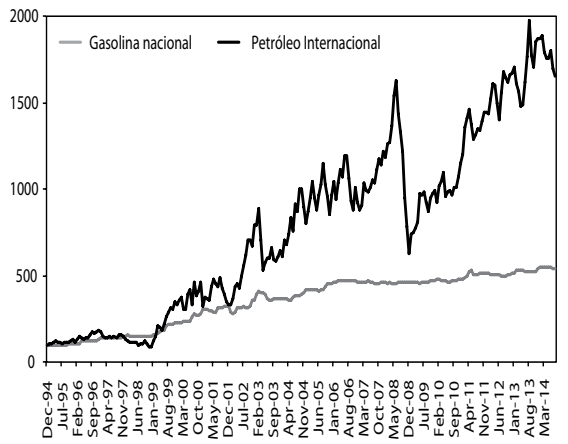

Evolução do preço do GLP nacional vs. petróleo internacional

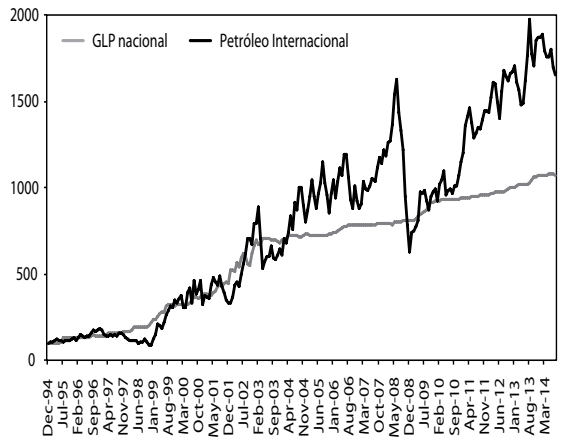

Evolução do preço do diesel nacional vs. petróleo internacional

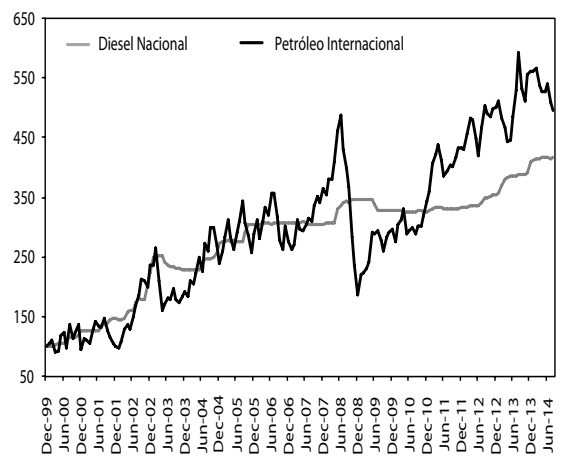

Fontes: IBGE e EIA.

solina, sobretudo após 2010, quando os veículos flex-fuel atingiram aproximadamente $40 \%$ da frota nacional (Orellano et al., 2014).

A contenção do preço da gasolina implica, portanto, limites ao preço do etanol, o qual algumas vezes tem se situado abaixo do custo operacional para algumas usinas $^{2}$. A consequência é visível nos números da indústria sucroalcooleira, cuja crise, no final de 2014, já afetava 96 das cerca de 400 usinas de açúcar e etanol. Destas, 11 estavam desativadas e em processo de falência, 53 em recuperação ju-

\footnotetext{
${ }^{2}$ PECEGE (2013). "PECEGE/CNA anunciam resultados do acompanhamento de custos de produção de cana-de-açúcar, açúcar e etanol da safra 2012/13 na região Centro-Sul”. Artigo disponível em: <http:// pecege.dyndns.org >. Acesso em: 26/10/2014.
} 


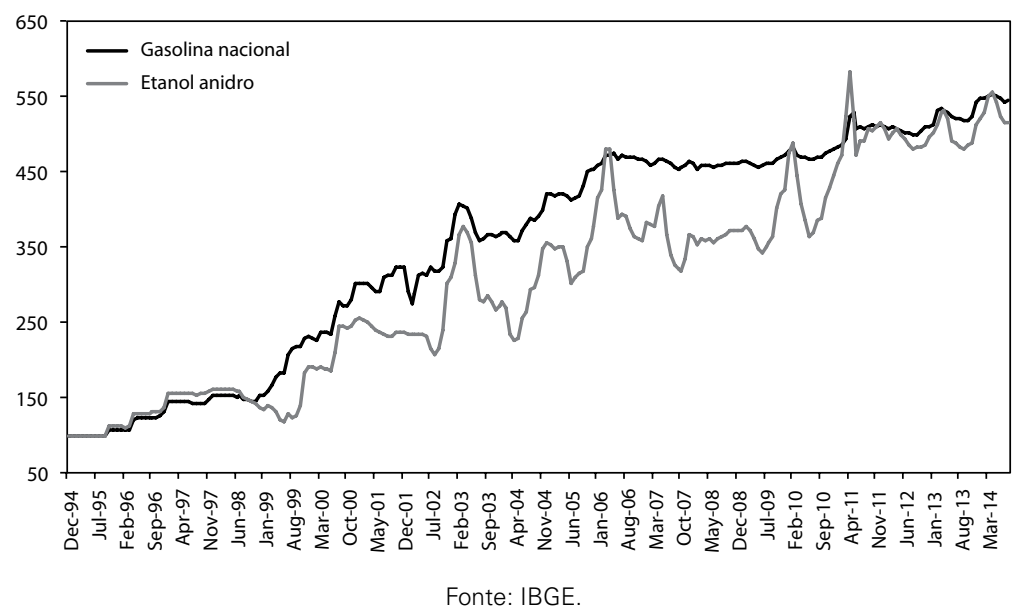

dicial e o restante com as atividades paralisadas, embora ainda solventes ${ }^{3}$. Não é possível imputar esses resultados negativos unicamente à política de controle do preço da gasolina, mas tudo indica que ela teve importante papel na derrocada de um dos mais importantes e competitivos setores da indústria brasileira.

A recente queda do preço do petróleo, posterior à análise quantitativa empreendida neste trabalho, confirma a hipótese de uso de preços administrados como instrumento auxiliar a uma política macroeconômica de curto prazo. Em um primeiro momento, a queda de preços foi tomada como um elemento positivo para a Petrobras, algo aparentemente paradoxal sendo esta uma empresa petrolífera. Ocorre que, devido à defasagem dos preços domésticos e sua função pública de zelar pelo suprimento de combustíveis, a Petrobras importava gasolina a um preço superior ao que a vendia no mercado doméstico. Nesse primeiro momento, cada centavo a menos no preço internacional resultava em uma redução do prejuízo da empresa.

A queda do preço do petróleo serviu também para criar as condições para a elevação da alíquota da Cide, que passou a ser fixada, no início do segundo mandato da Presidente Dilma, em R \$ 0,22 por litro de gasolina. A medida, contudo, foi parte de um pacote fiscal com o objetivo de equilíbrio das contas públicas, o que indica que a sua adoção foi mais motivada pela necessidade arrecadatória do que pelos seus efeitos na política setorial. Mais uma vez, nota-se a subordinação da política setorial aos ajustes macroeconômicos de curto prazo.

\section{Energia elétrica residencial}

Diferentemente do caso dos derivados de petróleo, o serviço de energia elétrica conta com um desenho regulatório clássico, em que uma agência autônoma, a Aneel, é responsável por estabelecer os reajustes de preços, obedecendo, para tanto,

\footnotetext{
${ }^{3}$ Batista, F. "Levantamento indica que há 30 usinas perto do default no país”. Valor Econômico, $29 / 09 / 2014$.
} 
a critérios previamente estabelecidos. Isso reduz a discricionariedade do Executivo na determinação dos preços da energia elétrica residencial.

Nota-se, na Figura 4, que os preços da energia elétrica residencial situaram-se, por quase todo o período analisado, acima do IGP-M, índice utilizado como referência para os reajustes de preços. Um primeiro salto ocorreu no momento das primeiras concessões aos operadores privados, em 1995, quando foram definidas as tarifas suficientes para remuneração do investimento privado. Posteriormente, após 2004, a concentração da contratação de energia termoelétrica nos leilões da Aneel gerou uma elevação de preços, que somente foi revertida por ocasião de leilões de grandes projetos estruturantes, como a Usina Hidroelétrica de Santo Antônio, em 2007 (Landau et al., 2013). Ainda assim, o elemento que mais explica a elevação de preços foi o aumento de encargos, da ordem de $295 \%$, no período entre 2001 e 2011, enquanto os custos de distribuição, geração e transmissão aumentaram, respectivamente, $35 \%$, $81 \%$ e $158 \%$ (Landau et al., 2013, p. 272).

O que mais chama a atenção na Figura 4 é a súbita e relevante queda de preços em 2012, resultado da Medida Provisória no 579, de setembro de 2012. Esta medida antecipou a renovação de contratos de concessão que venceriam entre 2015 e 2017, sem a necessidade de realização de nova licitação. Tratou-se, portanto, de medida excepcional, que retirou da concessão do serviço público o critério da impessoalidade e transparência do certame licitatório, e que, ademais, antecipou o impacto da renovação da concessão para o início de 2013.

Figura 4: Evolução do preço da energia elétrica e do IGP-M

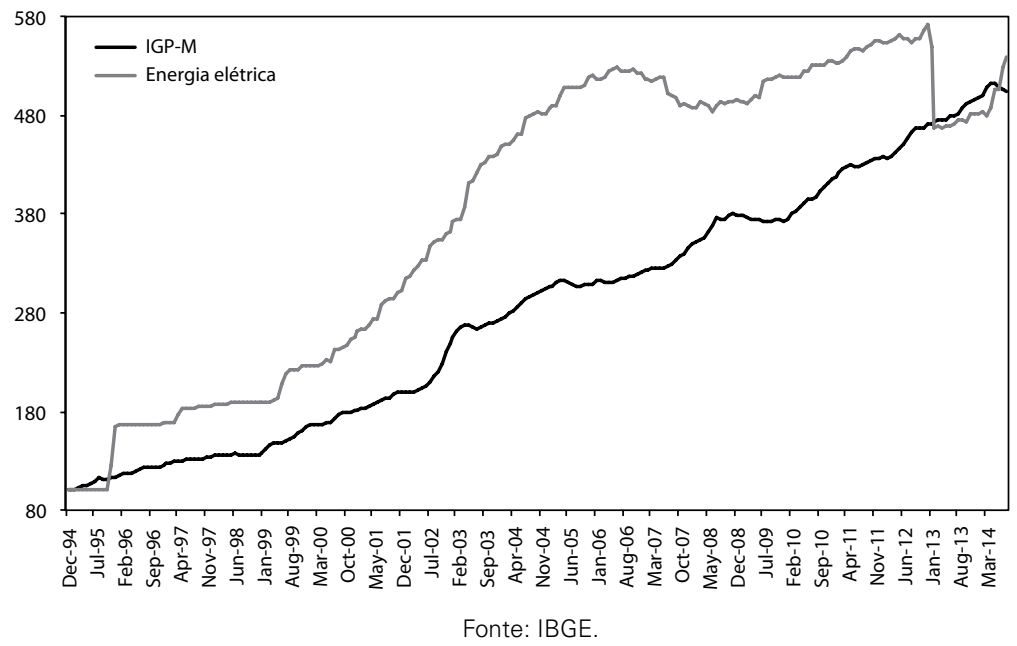

Este caso revela que, mesmo nos setores em que o modelo regulatório retira do governo a discricionariedade em determinar os preços do serviço público, há espaço para a ação discricionária, por meio de medidas excepcionais, até mesmo sem a consulta ao Legislativo, como é o caso de medidas provisórias. Embora a fundamentação da MP n 579 esteja inteiramente baseada em elementos de caráter 
setorial, como a modicidade tarifária e custos de operação, não se pode descartar que objetivos político-eleitorais ou de subordinação à política macroeconômica tenham influenciado a adoção da medida. De fato, os resultados dessa intervenção excepcional são consistentes com ambos. Os benefícios da renovação das concessões seriam somente sentidos após o término no primeiro mandato da Presidente Dilma, de tal modo que sua antecipação foi eleitoralmente conveniente, ainda que não fosse este o objetivo central para a adoção da medida. A redução das tarifas de energia elétrica residencial também contribuiu para conter o IPCA, que ameaçava ultrapassar o teto da meta de inflação, sendo, portanto, a medida provisória também consistente com o objetivo macroeconômico de controle inflacionário.

A hipótese de uso estratégico da MP no 579 é reforçada pelos custos regulatórios envolvidos na antecipação das concessões de energia elétrica. Dois problemas merecem menção. Primeiro, a mudança de regras do jogo, em prejuízo à rentabilidade do investidor privado, eleva risco regulatório e, portanto, os custos esperados de expropriação do investimento. É esta a preocupação básica que inspira o modelo regulatório de agências independentes, em que se procura criar um compromisso crível de não expropriação, a fim de criar incentivos ao investimento privado (Spiller e Tommasi, 2005). O segundo problema é de ordem econômico-financeira, decorrente do constrangimento da capacidade de investimento das empresas, o que deve levar a maior participação do Tesouro na capitalização do sistema Eletrobras. A crise hídrica de 2014 agravou este quadro e pegou as empresas que participaram da antecipação das concessões, em sua grande maioria estatais, em situação financeira delicada. A conta deste ajuste chegará em 2015, na forma de tarifas mais altas e provável socorro do Tesouro a essas empresas.

\section{Correios}

A análise da evolução dos preços dos Correios revela um padrão absolutamente distinto do observado em derivados de petróleo, ainda que em ambos o governo goze de discricionariedade na determinação de seus preços. Entre 2000 e 2014, os preços dos Correios acumularam desvios em relação ao IPCA que indicam um aumento relativo de aproximadamente $60 \%$ em seus preços, concentrado no início da década de 2000. No restante da série, os aumentos dos preços dos Correios preservaram essa diferença em relação à média dos preços que compõem o IPCA (Figura 5).

Os dados não oferecem elementos para se concluir que os preços no início da série, em 2000, estavam ajustados, de tal modo que não se pode descartar a hipótese de que o aumento observado não se tratava de mera correção de defasagem anterior. Pode-se, contudo, acrescentar as evidências de que não houve no período mudança de custos que justificassem tal aumento. A obrigação de universalização da entrega de cartas foi relativamente facilitada pela expansão da rede de transporte, em geral, e a tecnologia de informação tem permitido ganhos de eficiência no serviço de correios. Acrescente-se que a lucratividade dos Correios durante o período observado é expressiva, como atesta comunicado do presidente da própria empresa, Sr. Wagner Pinheiro de Oliveira. Em artigo publicado em 3 de junho de 
Figura 5: Evolução dos preços dos Correios e do IPCA

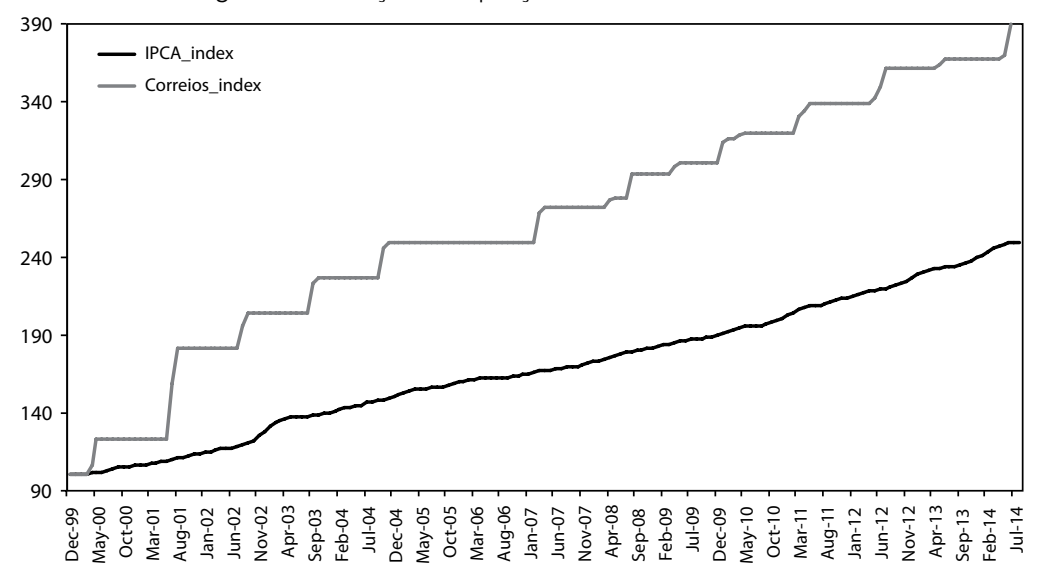

Fonte: IBGE.

2013, no jornal Brasil Econômico, o presidente dos Correios afirma que "Na contramão do caminho adotado pela USPS [empresa de correios estadunidense], a estatal brasileira vem acumulando, ano a ano, resultados financeiros positivos. Ao invés de ser subsidiada pelo governo federal, retorna aos cofres públicos consideráveis quantias em dividendos. [...]”.

Enquanto a lucratividade da Petrobras ruiu nos quatro anos do primeiro mandato da Presidente Dilma, a dos Correios segue alta. O comportamento dos preços administrados de derivados de petróleo e o do serviço dos Correios é absolutamente consistente com os resultados financeiros e contábeis das duas empresas.

A questão que se coloca é por que comportamento tão distinto em setores em que o governo igualmente goza de discricionariedade na determinação de seus preços. A resposta pode estar, mais uma vez, no uso de preços administrados para fins de controle inflacionário ou, mais precisamente, para manter o IPCA próximo à meta de inflação. Enquanto a gasolina representa 3,7745 na composição do IPCA, o serviço dos Correios tem peso insignificante, de apenas 0,0118. Em outras palavras, para fins de atendimento da meta de inflação, o efeito de se restringir o preço da gasolina é 320 vezes maior do que o de se restringir aumentos nos preços do serviço dos Correios. O padrão distinto de evolução dos preços do serviço dos Correios e da gasolina pode ser explicado, portanto, pelo seu papel no controle espúrio, diga-se de passagem — da inflação. Esta evidência, ademais, é absolutamente consistente com o observado entre os derivados de petróleo, particularmente na comparação entre gasolina e diesel. Mais uma vez, tem-se evidência de subordinação da política setorial, na determinação de preços administrados, aos interesses da política macroeconômica de curto prazo, de modo, conforme já argumentado, ineficaz aos interesses da política macroeconômica de médio e de longo prazo.

\section{Passagens de ônibus urbanos}

O último dos preços administrados de que trata este artigo são as passagens de ônibus urbanos, cuja discricionariedade de reajuste é alocada ao poder munici- 
pal. O interesse pela análise desta série de preços é distinguir a racionalidade de uso da discricionariedade na determinação de preços para fins político-eleitorais. Diferentemente dos preços administrados sob o controle federal, as passagens de ônibus urbanos não devem ter suas variações condicionadas pelo atendimento à meta de inflação, um responsabilidade do governo federal, mas podem ser afetadas pelo calendário eleitoral, dado o impacto dos preços de transporte municipal sobre a avaliação do prefeito em exercício. O fato de o calendário eleitoral municipal ser distinto dos calendários estadual e federal auxilia na estratégia de identificação desses efeitos, devendo-se esperar, para o caso de uso político-eleitoral da discricionariedade de precificação, que não ocorram aumentos nos anos de eleição municipal.

Os dados dos preços de passagens de ônibus urbanos são disponíveis para as capitais incluídas no cálculo do IPCA. Destas foram selecionadas algumas mais representativas, cuja evolução de preço foi comparada com o próprio IPCA e com o preço local do diesel, um importante componente do custo de transporte urbano. Segue-se uma síntese dos resultados observados ${ }^{4}$.

De modo geral, os preços das passagens de ônibus urbanos tendem a ser reajustados em anos ímpares, em que não há eleições municipais ou estaduais. Esse padrão é mais evidente em São Paulo (Figura 6) e Fortaleza (Figura 7), em que se nota a predominância de uma escalada regular, de reajustes a cada dois anos, havendo casos esporádicos em que as passagens de ônibus ficaram sem reajuste por quatro anos. Nesses casos, sugere-se a hipótese, não explorada por este artigo, de que o alinhamento político entre a prefeitura e o governo estadual ou federal explique a incidência ou não de reajuste em anos de eleição para governador e presidente.

Não há, por outro lado, um padrão claro de afastamento dos preços desse serviço público e seus custos de produção. Nota-se que, embora os preços das passagens de ônibus tenham ficado acima do IPCA, regularidade observada em todas as capitais analisadas, sua variação ficou muitas vezes abaixo da do diesel, um importante componente de seus custos de produção. Esse comportamento apenas não é visível nos casos de Curitiba e Fortaleza (Figura 7), em que a série de óleo diesel inicia-se apenas em 2008. Tomando-se as demais capitais como referência, nota-se que o aumento mais importante do óleo diesel deu-se antes de 2008 e, portanto, não pode ser observado para o caso dessas duas capitais.

Em síntese, há indícios de que os preços das passagens de ônibus urbanos atendem a uma periodicidade subordinada ao calendário político-eleitoral, mas não há desvios significativos de seus preços em relação a seus custos de produção, o que poderia trazer prejuízos à política de transportes. É também digno de nota que esse resultado geral encobre particularidades de cada município, seja na periodicidade de reajustes, seja em sua intensidade. Essas diferenças podem decorrer da regulação local dos contratos de concessão de transporte urbano, que podem estipular maior ou menor discricionariedade ao poder público municipal, e das cir-

\footnotetext{
${ }^{4}$ Por restrição de espaço, são apresentados, na forma de figuras, apenas os dados para as capitais de São Paulo e Fortaleza. Os resultados para as demais capitais estão disponíveis junto aos autores.
} 
Figura 6: Evolução do IPCA e dos preços do óleo diesel e da passagem de ônibus municipal na cidade de São Paulo
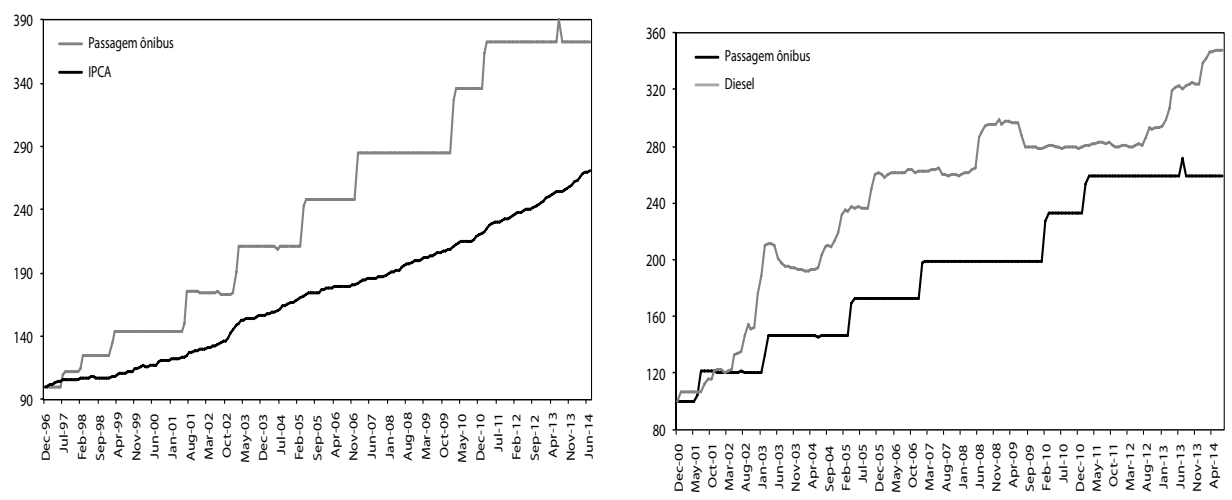

Fonte: IBGE.

Figura 7: Evolução do IPCA e dos preços do óleo diesel e da passagem de ônibus municipal na cidade de Fortaleza
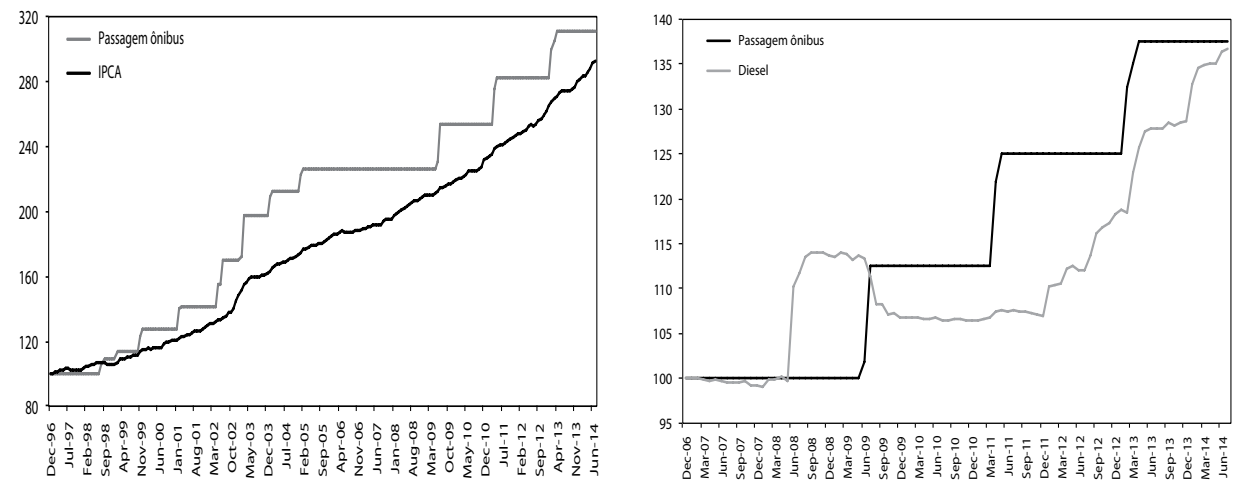

Fonte: IBGE.

cunstâncias políticas locais. A investigação detalhada dessas causas, contudo, ultrapassa as ambições deste artigo.

\section{CONSIDERAÇÕES FINAIS E IMPLICAÇÕES PARA A POLÍTICA PÚBLICA}

A política de reajustes de preços administrados do primeiro mandato da Presidente Dilma foi marcada pela subordinação da política setorial, à qual os preços 
relativos administrados deveriam servir, e à política macroeconômica de curto prazo, em particular ao atendimento das metas de inflação. A estratégia é, ao mesmo tempo, ineficaz para o controle da inflação a médio e longo prazos, como indicam as projeções de inflação para 2015, e também prejudicial às decisões de investimento e consumo, que se apoiam nos preços relativos para a sua orientação. A crise por que passa a indústria de etanol exemplifica os efeitos microeconômicos deletérios da política de contenção do preço da gasolina, que minou a sua rentabilidade e abortou projetos de investimento no setor sucroalcooleiro.

O papel dos preços administrados como freio à inflação começa a ser notado já no segundo mandato do Presidente Lula, em 2007, momento em que se inicia uma inflexão na política macroeconômica, de relaxamento progressivo das políticas fiscal e monetária. Foi, contudo, no primeiro mandato da Presidente Dilma que o grau de intervenção do Executivo sobre os preços administrados atingiu o seu ápice, tornando-se uma política explicitamente subordinada ao controle da inflação, como ilustra o caso da desoneração da Cide e a MP no 579, ambas em 2012.

Trata-se de caso de abuso - e não de uso — da discricionariedade concedida ao Poder Executivo de determinar preços de diversos serviços, visto que este poder deveria atender aos propósitos da política setorial que deu fundamento à sua alocação ao Executivo. A questão que se coloca é como evitar a ocorrência desses desvios de política e, ao mesmo tempo, preservar os graus de liberdade da política setorial.

Há duas alternativas para se contornar este problema. A primeira seria a redução da discricionariedade para a determinação de preços em curto prazo, mantendo-se, contudo, a capacidade de o Estado orientar a precificação de longo prazo de setores estratégicos, tão fundamentais para as políticas setoriais, sejam elas de caráter ambiental ou produtivo. Um modo de reduzir essa discricionariedade seria a mudança regulatória, como parece desejável no caso de tarifas de ônibus urbanos, ou o estabelecimento de regras de reajuste de preços, transparentes e cuja mudança represente um custo político ao governo em exercício. Esta política de reajuste chegou a ser proposta pela própria Petrobras, no final de 2013, mas foi rechaçada pelo então Ministro da Fazenda, Guido Mantega.

Entretanto, a análise aqui empreendida mostra que mesmo a redução da discricionariedade do Executivo na determinação de preços, como ocorre no setor elétrico, não é suficiente para impedir o abuso do Executivo na determinação de preços administrados. A MP $\mathrm{n}^{\circ} 579$, que resultou em queda dos preços da energia elétrica residencial, rompeu com as regras do jogo que orientavam os investimentos de longo prazo. Além disso, a mudança foi conveniente ao governo em exercício do ponto de vista político-eleitoral, visto que os benefícios políticos da redução das tarifas foram antecipados para o primeiro mandato, em tempo de fortalecerem o projeto de reeleição. Este é mais um argumento em favor das limitações ao escopo e alcance das medidas provisórias, que, neste caso, parecem criar um problema ao próprio Executivo no longo prazo, que sofre com as escolhas estratégicas do governante incumbente. Em outras palavras, a limitação ao uso de medidas provisórias não se justifica apenas por um problema de equilíbrio entre os poderes, mas 
também pelo conflito entre os interesses do governante em exercício e os dos governantes futuros.

A segunda alterativa - de custos operacionais e políticos bastante inferiores - seria modificar os incentivos para que o governo em exercício utilize sua discricionariedade de modo menos nocivo à política setorial que dá fundamento ao poder de determinar preços. A tentação em utilizar os preços administrados para o controle da inflação - ou, mais precisamente, para o atendimento da meta de inflação - decorre do fato de estes serem importantes componentes do IPCA, índice utilizado como referência para a meta de inflação. De fato, a análise dos preços administrados indica que os desvios de preço ocorrem com maior intensidade quanto maior a importância desses preços na composição do IPCA, sendo emblemáticas as comparações entre gasolina, diesel e Correios. Retirar os preços administrados do índice que serve de referência para a meta de inflação é um meio simples e direto de modificar esses incentivos.

Esta medida é também desejável do ponto de vista da política monetária, visto que preços administrados são, por definição, insensíveis às condições de demanda e, dessa forma, não respondem aos instrumentos de política monetária sob o controle do Banco Central. Incluí-los no índice que baliza a meta de inflação gera sinais equivocados para a política monetária a ser seguida pelo Banco Central, que pode utilizar política excessivamente restritiva se preços administrados forem reajustados acima dos preços livres (e excessivamente leniente no caso contrário) (Mendonça, 2007). Foi o que ocorreu entre 2000 e 2006, período em que preços administrados pressionaram a inflação, tendo o Banco Central respondido com forte elevação da taxa de juros, com efeitos generalizados sobre a economia, mas com resultados pífios sobre a variável que lhe havia dado causa. Retirar os preços administrados do índice de referência para a meta de inflação é uma medida que atende, simultaneamente, à eficácia da política monetária e à eficiência microeconômica. Há, obviamente, argumentos em contrário a esta medida, mas é difícil acreditar que possam ser suficientes para contrabalançar esses benefícios.

\section{REFERÊNCIAS BIBLIOGRÁFICAS}

ALVES, P.; RODRIGUES FIGUEIREDO, F.M.; JUNIOR, A.; PEREZ, L.P. (2013). Preços Administrados: projeção e repasse cambial (No. 305). Central Bank of Brazil, Research Department.

CASTRO, A. B. D. (1968). O Crescimento da Economia Brasileira ea Demanda de Energia Elétrica. Energia, Tecnologia e Desenvolvimento. Petrópolis, Vozes.

LANDAU, E.; DUTRA, J.; SAMPAIO, P. (2013). “O estado e a iniciativa privada no setor elétrico: uma análise das duas últimas décadas (1992-2012). In: Chrysostomo de Oliveira Filho, L.; Oliveira, G. Parcerias público-privadas - experiências, desafios e propostas. Rio de Janeiro: LTC, 2013, pp. 255-286.

ERBER, F. S. (1993) “A indústria petroquímica: crise, regulação e mercado“. In: Workshop sobre estratégias setoriais, Rio de Janeiro: Instituto Nacional de Altos Estudos (mimeo).

HAYEK, F. A. (1945). The use of knowledge in society. The American economic review, 519-530.

MENDONÇA, H. F. D. (2007). Metas de inflação e taxa de juros no Brasil: uma análise do efeito dos preços livres e administrados. Revista de Economia Política, 27(3), 107. 
ORELLANO, V. F.; SOUZA, A. D. N.; AZEVEDO, P. F. (2013). Elasticidade-preço da demanda por etanol no Brasil: como renda e preços relativos explicam diferenças entre estados. Revista de Economia e Sociologia Rural,51(4), 699-718.

SPILLER, P. e TOMMASI, M. (2005). "The Institutions of Regulation. An Application to Public Utilities.” In: Claude MÉNARD e Mary M. SHIRLEY (eds). Handbook of New Institutional Economics. Springer: 515-544.

WONGTSCHOWSKI, P. (1998) 'Técnicas de redução de vulnerabilidade na indústria química”. Tese de doutorado, Universidade de São Paulo, Escola Politécnica, São Paulo (mimeo). 